\title{
Identification and characterization of the gene for Drosophila L3 ribosomal protein
}

\author{
H.Y. Edwin Chan ${ }^{\text {a }}$, Yong Zhang ${ }^{\mathrm{a}, 1}$, J.D. Hoheisel ${ }^{\mathrm{b}}$, Cahir J. O'Kane ${ }^{\mathrm{a}, *}$ \\ a Department of Genetics, University of Cambridge, Downing Street, Cambridge, CB2 3EH, UK \\ b Deutsches Krebsforschungszentrum, Im Neuenheimer Feld 506, D-69120 Heidelberg, Germany
}

Received 20 October 1997; accepted 6 March 1998; Received by D. Lilley

\begin{abstract}
A cDNA clone that encodes a Drosophila homologue of ribosomal protein L3 was isolated from a Drosophila ovary gridded cDNA library. The Drosophila ribosomal protein L3 gene $(R p L 3)$ is highly conserved with ribosomal protein L3 genes in other organisms. It is a single copy gene and maps to position $86 \mathrm{D} 5-10$ on polytene chromosomes. A Minute gene in this region, $M(3) 86 D$, is a possible candidate to encode RPL3. RPL3 message is expressed ubiquitously. A partial RPL8 cDNA clone was also isolated and mapped to 62F. C 1998 Elsevier Science B.V. All rights reserved.
\end{abstract}

Keywords: Minute; cDNA cloning; $P 1$ genomic mapping; Intron/exon mapping; $R p L 3$; $R p L 8$; mRNA

\section{Introduction}

Eukaryotic ribosomes are the sites of protein synthesis. Each ribosome is composed of two subunits, the $60 \mathrm{~S}$ and the $40 \mathrm{~S}$ subunit. Each subunit consists of ribosomal proteins and ribosomal RNA molecules (Wool et al., 1996).

Most Drosophila ribosomal protein genes are singlecopy genes (Kay and Jacobs-Lorena, 1987; Baumgartner et al., 1993; McNabb and Ashburner, 1993). At present, approximately 40 ribosomal protein genes in Drosophila have been sequenced (The FlyBase Consortium, 1997). However, most of them have not been genetically characterized in detail (The FlyBase Consortium, 1997). More

\footnotetext{
* Corresponding author. Tel: +44 1223 333177; Fax: +44 1223 333992; e-mail: c.okane@gen.cam.ac.uk

${ }^{1}$ Present address: Department of Biology, University of Utah, Salt Lake City, UT 84112, USA.
}

than 10 ribosomal protein loci are associated with a dominant Minute bristle phenotype and recessive lethality (e.g. Kongsuwan et al., 1985; Andersson et al., 1994; Schmidt et al., 1996; The FlyBase Consortium, 1997); two of them give rise to a tissue overgrowth phenotype [summarized by Chan et al. (1997)]. However, not all mutations in ribosomal protein genes cause a Minute phenotype (e.g. RpS14, Dorer et al., 1991).

Ribosomal protein L3 $(R p L 3)$ is a component of the $60 \mathrm{~S}$ ribosome subunit. Some mutations in the yeast $R p L 3$ gene give rise to resistance to trichodermin, an inhibitor of ribosome peptidyl transferase activity, implying that RPL3 protein is situated in the vicinity of the peptide bond-forming site in the ribosome (Fried and Warner, 1981; Schultz and Friesen, 1983). Here, we report the cloning of a novel Drosophila $R p L 3$ gene, which is conserved between eukaryotes and prokaryotes. The cytological location of Drosophila $R p L 3$ is in the vicinity of a candidate Minute mutation, $M(3) 86 D$.

\section{Materials and methods}

\subsection{Isolation of a RPL3 $c D N A$ clone}

A eukaryotic translational initiation factor $5 \mathrm{~A}$ (eIF5A) cDNA fragment (Koettnitz et al., 1994) was labelled with $\left[\alpha-{ }^{32} \mathrm{P}\right] \mathrm{dATP}$ using random priming and 
then used to screen two gridded filters carrying clones from a $0-8 \mathrm{~h}$ Drosophila embryonic cDNA library (Brown and Kafatos, 1988; Hoheisel et al., 1991) at low stringency. Hybridization was carried out at $68^{\circ} \mathrm{C}$ overnight in hybridization buffer [6× SSC; $0.5 \%$ SDS; $200 \mathrm{mg} / \mathrm{ml}$ salmon sperm DNA; 0.1\% $N$-lauroylsarcosine and 1\% Southern blocking solution (Boehringer Mannheim)]. Filters were then washed with $4 \times$ SSC, $0.1 \%$ SDS at room temperature for $2 \mathrm{~h}$ before autoradiographic exposure.

\subsection{Sequence analysis}

Cycle DNA sequencing reactions and sequence analysis were performed as described in Chan et al. (1997). Universal primers SP6 and T7, which annealed to sequences in the pNB40 vector (Brown and Kafatos, 1988), were used to sequence the $5^{\prime}$ and $3^{\prime}$ ends of the cDNA insert, respectively. Internal sequencing primers of $R P L 3$ used were: a, 5' CTC CCT TCG GTC TGC GTG 3'; b, 5' CAG CTG AAC GGC GGC TCC 3'; c, 5' CTT CGG CCA GGA CGA GAT G 3'; d, 5' CAA GGG CTG CTG CAT CGG C 3'; e, 5' CTT GTC GGC AGG GGT CTG 3'; f, 5' CCA GCG CCG ATG CGG TAG 3'; g, 5' GCG GAT CTG CGA ATG GGC 3'; h, 5' GCA GGT CAG ATG GAC TGG C 3'; i, 5' GTA CTC GGT GGA GGC GTT G 3' (Fig. 1A).

\subsection{In-situ hybridization to polytene chromosomes}

Double-stranded RPL3 cDNA probe was labelled with biotin-16-dUTP and prepared by nick translation (Sambrook et al., 1989). In situ hybridization to polytene chromosomes was performed according to Engels et al. (1986) with minor modifications.

\subsection{Genomic PCR analysis}

Genomic PCR reactions were performed by using either a single colony of each relevant bacterial $P 1$ genomic clone or single fly genomic DNA (Gloor et al., 1993 ) as template, and different combinations of oligonucleotides as primers (Fig. 1A). Pl bacterial cells were picked from kanamycin-containing $(25 \mu \mathrm{g} / \mathrm{ml})$ agar plates and transferred to $0.5-\mathrm{ml}$ microcentrifuge tubes containing PCR reaction mix $[1 \times$ PCR buffer (Promega); $1.25 \mathrm{mM} \mathrm{MgCl}_{2} ; 400 \mu \mathrm{M}$ dNTP mix and 1 unit of Taq DNA polymerase (Promega)] before amplification. One fiftieth of a single fly DNA preparation or an entire single colony preparation was used for each PCR reaction. PCR reactions were performed as follows: $15 \mathrm{~s}$ at $98^{\circ} \mathrm{C}$, and then $30 \mathrm{~s}$ at $58^{\circ} \mathrm{C}, 1.5 \mathrm{~min}$ at $72^{\circ} \mathrm{C}$, $30 \mathrm{~s}$ at $95^{\circ} \mathrm{C}$ for 30 cycles.

\subsection{Southern blot analysis}

A $R P L 3$ cDNA fragment was generated by restriction digestion of the pNB40 RPL3 plasmid with HindIII and $E c o$ RI enzymes. The fragment was then purified and labelled with $\left[\alpha-{ }^{32} \mathrm{P}\right] \mathrm{dATP}$ using random priming (Sambrook et al., 1989).

Drosophila genomic DNA was prepared from a Canton S strain essentially according to Ashburner (1989). Genomic DNA was digested with BglII, EcoRI, HindIII, PstI and $X b a \mathrm{I}$ separately and then blotted, hybridized and detected according to Sambrook et al. (1989).

\subsection{Northern blot analysis}

Total RNA was prepared from 0-16-h-old Canton S strain embryos according to Andres and Thummel (1994). The same $\left[\alpha_{-}{ }^{32} \mathrm{P}\right] \mathrm{dATP}$ labelled HindIII-EcoRI cDNA fragment (as described in Section 2.5) was used as probe. Northern hybridization was carried out according to Sambrook et al. (1989).

\subsection{In-situ hybridization to whole-mount embryos}

Single-stranded DNA probes labelled with digoxygenin-11-dUTP (Boehringer Mannheim) were prepared by PCR using a RPL3 cDNA fragment as template and either SP6 primer to label the sense strand or T7 primer to label the anti-sense strand as described by Tautz et al. (1992). Under our labelling and detection conditions, both sense and anti-sense probes were equally sensitive, and a 10- $\mu$ l spot of a 1:100 000 dilution could be detected using CSPD ${ }^{\circledR}$ chemiluminescence (Tropix). In-situ hybridization was performed essentially according to Tautz and Pfeifle (1989).

\section{Results and discussion}

\subsection{Isolation of an RPL3 cDNA clone}

A low-stringency screen was set up to search for a homologue of eukaryotic translational initiation factor eIF5 A in Drosophila melanogaster. Seven putative positive clones were found. $5^{\prime}$ and $3^{\prime}$ ends of all seven putative positive clones were sequenced using SP6 and T7 primers, respectively. None of them showed any sequence similarity to eIF5 $\mathrm{A}$. Nevertheless, one of the false positive cDNA clones was found to encode an L3 Drosophila ribosomal protein (RPL3) (see below). In the same screening exercise, a partial cDNA clone of ribosomal protein gene $\mathrm{L} 8(R p L 8)$ was also isolated and mapped to $62 \mathrm{~F}$ (data not shown); the RPL8 cDNA clone was not investigated further here. 
Fig. 1. (A) Nucleotide sequence of $R P L 3$ cDNA clone and its deduced amino acid sequence. Nucleotide position of the $R P L 3$ open reading frame (counted from the first nucleotide of the first ATG) is indicated above the nucleotide sequence and followed by the amino acid position; the RPL3 signature is italicized and in bold. The stop codon is designated as ' $*$ '. The poly A signal is underlined, and the final (a) indicates the position of the poly A tail. Positions and 5'-3' directions of primers are represented by arrows above the sequence. (B) Comparison of the ribosomal protein L3 signature of Drosophila RPL3 protein with the rat (X62166); C. elegans (Z69337); Saccharomyces cerevisiae (J01351); Schizosaccharomyces pombe RPL3-1 (U00798) and RPL3-2 (X57734) ribosomal protein L3 homologues. Amino acid residues that are identical in at least four of these sequences are boxed. The Genbank Accession No. for the Drosophila RPL3 cDNA is AF016835. 


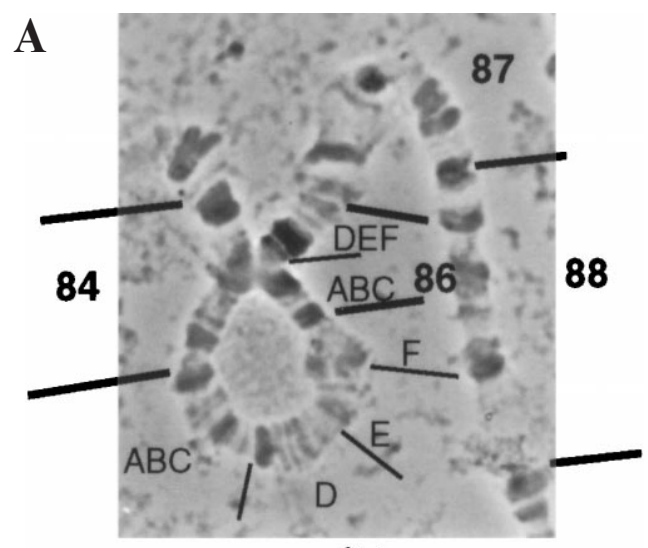

85

B

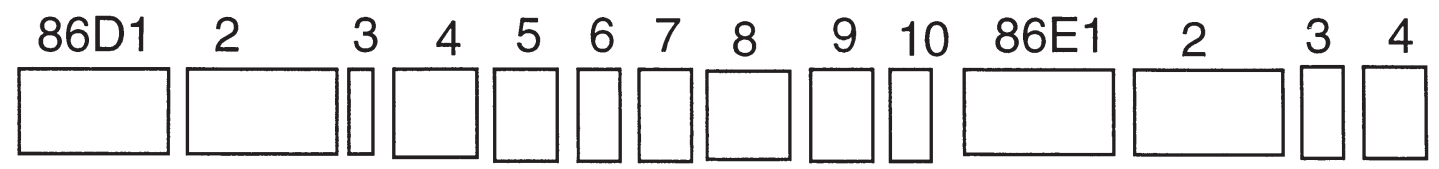

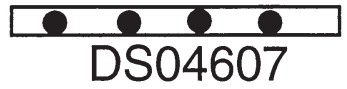

DS04776
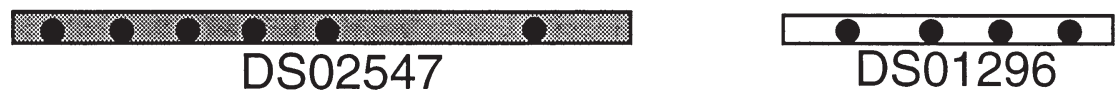

Dm02115 Dm02581 Dm02118
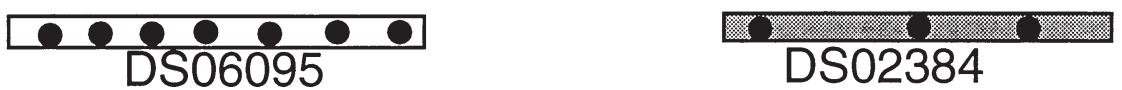

Fig. 2. (A) In-situ hybridization of RPL3 cDNA to polytene chromosomes. Polytene map divisions (Lindsley and Zimm, 1992) are shown. (B) PCR-based $P 1$ mapping of $R p L 3$. RpL3-negative $P 1$ clones are represented by open boxes. $R p L 3$-positive $P 1$ clones are represented by shaded boxes. Black dots represent sequence-tagged sites (STSs). The three labelled STSs and the P1 clones shown are documented in Encyclopaedia of Drosophila Release 3.1 (1996).

\subsection{Sequence analysis of RPL3 $c D N A$ and RPL3 protein}

The RPL3 cDNA clone was sequenced completely in both strands. It contains $1381 \mathrm{bp}$, including a $5^{\prime}$ UTR of $33 \mathrm{bp}$, a coding region of $1251 \mathrm{bp}$, and a 3' UTR of $97 \mathrm{bp}$ (see Section 3.4). The predicted initiation codon occurs in the context AGACATG which is similar to the consensus sequence at initiation codon in Drosophila (Cavener, 1987). The RPL3 open reading frame (ORF) starts with an ATG codon and stops with a TAA codon. A putative polyadenylation signal is situated $70 \mathrm{bp}$ downstream of the ORF (Fig. 1A).

The predicted RPL3 protein consists of 416 amino acid residues (Fig. 1A). The deduced molecular mass of the protein is $46886 \mathrm{Da}$, and the protein is basic with a calculated isoelectric point of 10.68 .

BLASTX and ALIGN searches showed that RPL3 has $74.4 \%$ identity to its rat homologue (Kuwano and Wool, 1992), 70.9\% to its Caenorhabditis elegans homologue (Zhu et al., 1996), 64.3\% to its Saccharomyces cerevisiae homologue (Schultz and Friesen, 1983), 65.3\% to its Schizosaccharomyces pombe homologue RpL3-1 (Liebich et al., 1994) and $65.1 \%$ to its Schizosaccharomyces pombe homologue RpL3-2 (Liebich et al., 1994). A ribosomal protein L3 signature (Bairoch, 1993) is also present in the middle of the RpL3 protein at residues 211-234 (Fig. 1B). 


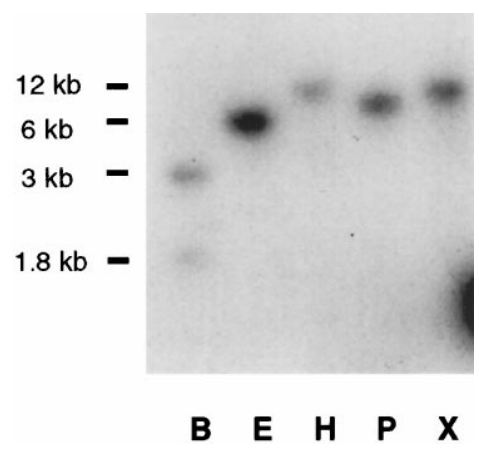

Fig. 3. Genomic Southern Hybridization of $R P L 3$ cDNA probe to digests of Canton S genomic DNA. B, Bg/II; E, EcoRI; H, HindIII; $\mathrm{P}$, Pst $\mathrm{I}$ and $\mathrm{X}, X b a \mathrm{I}$.

\subsection{Cytological location and genomic structure of $\mathrm{RpL} 3$}

$R p L 3$ was mapped to the region including the right of $86 \mathrm{D}$ and the left of $86 \mathrm{E}$ on polytene chromosomes (Fig. 2A). Genomic DNA isolated from a Canton S strain was digested with five different restriction enzymes and hybridized with the a RPL3 cDNA probe. In most digests, only one genomic fragment was detected (Fig. 3). The only exception was that two Bg/II fragments were detected (Fig. 3). This is consistent with the sequence data of the cDNA clone that there is a $B g / \mathrm{II}$ site at nucleotides $848-853$. These data suggest that $R p L 3$ is a single copy gene.

To map $R p L 3$ in more detail, PCR-based mapping was performed using nine $P 1$ clones in this region as template and oligonucleotides $\mathrm{b}$ and $\mathrm{f}$ (Fig. 1A) as primers. A genomic fragment with a size of about $300 \mathrm{bp}$ was amplified from three $P 1$ clones, DS02547, DS07339 and DS02384 (Fig. 2B). The other $P 1$ templates used (Fig. 2B) failed to give any PCR product. DS07339 has been mapped cytologically to 86D5-10 (Encyclopaedia of Drosophila Release 3.1, 1996). By combining the results of cytological mapping and PCR-based mapping, the cytological location of $R p L 3$ is refined to 86D5-10.

To determine whether introns are present in $R p L 3$, different oligonucleotides were used as PCR primers on genomic and cDNA templates (Table 1). These results suggest: (1) $1.2 \mathrm{~kb}$ of intronic sequence located somewhere between nucleotides 301 and 1139; (2) $0.9 \mathrm{~kb}$ of intronic sequence between nucleotides 301 and 852; (3) $0.6 \mathrm{~kb}$ of intronic sequence between nucleotides 301 and 490; and (4) $0.25 \mathrm{~kb}$ of intronic sequence between nucleotides 648 and 903. This demonstrates at least three introns in the RPL3 cDNA clone: $0.6 \mathrm{~kb}$ of intron sequence between nucleotides 301 and $490 ; 0.3 \mathrm{~kb}$ of intron sequence between nucleotides 490 and 567; and $0.25 \mathrm{~kb}$ of intron sequence between nucleotides 852 and 903 (Fig. 1A).

A Minute mutation, $M(3) 86 D$, has been localized in region 86D (Encyclopaedia of Drosophila Release 3.1, 1996; The FlyBase Consortium, 1997). RpL3 is, at present, the only ribosomal protein gene that has been found in this region. This suggests that $R p L 3$ may correspond to $M(3) 86 D$. Apart from $M(3) 86 D$, there are at least eight more genes in this region that have not been studied molecularly (Encyclopaedia of Drosophila Release 3.1, 1996; The FlyBase Consortium, 1997). They are E(var)3-14, E(var) 113, $f_{s}(3) 6284$, l(3)04629, l(3)09656, l(3)10419, $\mathrm{mgr}$ and tho. Moreover, five more lethal $P$-element insertions in this region have not been assigned to complementation groups (Encyclopaedia of Drosophila Release 3.1, 1996; The FlyBase Consortium, 1997). They are l(3)03445, l(3)rM060, l(3)rK137, l(3)rM007 and P\{ryl\}R311.1. $R p L 3$ could also potentially correspond to any of these mutations.

\subsection{Analysis of RPL3 transcript}

A single band of $1.6 \mathrm{~kb}$ was detected on a Northern blot probed with RPL3 cDNA (data not shown). The size of the RPL3 cDNA clone is $1381 \mathrm{bp}$ excluding the poly(A) tail. A poly(A) tail (260-300 nucleotides) is also present in most mature mammalian mRNAs (Birnstiel et al., 1985). Since the size of the band on the Northern blot and is of a similar length of the sum of the cDNA clone and a typical poly (A) tail, it is possible that the existing cDNA clone encodes a full-length $R P L 3$ cDNA. To detect longer RPL3 cDNA clones, a BLASTN search of Drosophila nucleotide sequences (Berkeley Drosophila Genome Project, pers. commun.) was performed, using the existing RPL3 cDNA sequence as query. Fifty-three Drosophila EST clones with a score

Table 1

PCR-based intron/exon mapping of $R p L 3$

\begin{tabular}{llll}
\hline Primers (position of 3' base) & Size of genomic product $(\mathrm{kb})$ & Size of cDNA product $(\mathrm{kb})$ & Size difference $(\mathrm{kb})$ \\
\hline $\mathrm{a}(301)+\mathrm{e}(1139)$ & $2.0^{\mathrm{a}}$ & 0.8 & 1.2 \\
$\mathrm{a}(301)+\mathrm{f}(852)$ & $1.6^{\mathrm{a}}$ & 0.7 & 0.9 \\
$\mathrm{a}(301)+\mathrm{g}(490)$ & $0.8^{\mathrm{a}, \mathrm{b}}$ & 0.3 & 0 \\
$\mathrm{~b}(567)+\mathrm{f}(852)$ & $0.3^{\mathrm{ab}}$ & 0.3 & 0 \\
$\mathrm{c}(648)+\mathrm{i}(903)$ & $0.5^{\mathrm{ab}}$ & 0.25 & 0.25 \\
\hline
\end{tabular}

${ }^{\mathrm{a} C}$ Canton $\mathrm{S}$ single fly genomic DNA template.

${ }^{\mathrm{b}} \mathrm{Pl}$ clone DS02384 single colony template. 


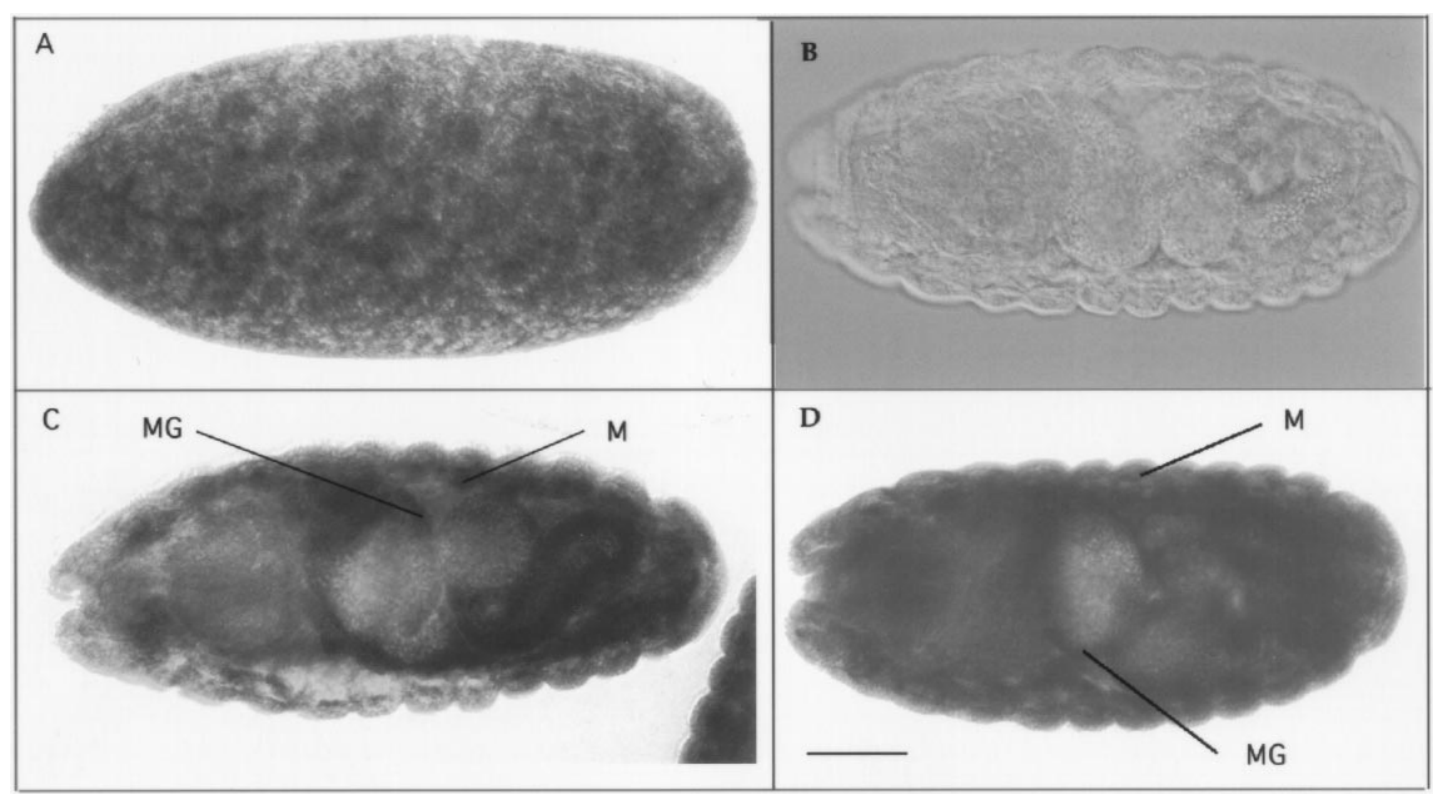

Fig. 4. Expression of $R P L 3$ in Drosophila embryos. (A) A preblastoderm embryo hybridized with the $R p L 3$ antisense probe and developed for $1 \mathrm{~h}$. (B) A stage 17 embryo hybridized with the $R p L 3$ sense probe and developed for $1 \mathrm{~h}$. Stage 16 embryos hybridized with the antisense probe and developed for (C) $15 \mathrm{~min}$ and (D) $1 \mathrm{~h}$. MG, midgut; M, muscle. The scale bar represents $50 \mu \mathrm{m}$.

of at least $95 \%$ sequence identity were found, but none of them contained a $5^{\prime}$ end longer than that of the existing cDNA clone.

\subsection{In-situ hybridization to whole-mount embryos}

RPL3 messenger RNA was expressed ubiquitously throughout embryogenesis. Expression was first detected as a maternal component at preblastoderm stages (Fig. 4A). Later in embryogenesis, RPL3 was also expressed ubiquitously but at higher levels in the midgut, hindgut and in muscle (Fig. 4C and D). No signal was detected using a control sense probe (Fig. 4B).

\section{Conclusions}

A Drosophila RPL3 cDNA clone has been isolated in this study and is highly conserved with $R p L 3$ genes in other organisms. Like most Drosophila ribosomal protein genes, $R p L 3$ is a single-copy gene. The ubiquitous expression of $R P L 3$ message is consistent with its role in general protein translation.

\section{Acknowledgement}

We thank Dr Dorian Bevec for the gift of the human eIF5 $A$ cDNA clone. H.Y.E.C. has been supported by a scholarship from the Croucher Foundation. Y.Z. was supported by a grant from the Medical Research Council to Prof. Michael Ashburner and Dr David Gubb.

\section{References}

Andersson, S., Saeboe-Larssen, S., Lambertsson, A., Merriam, J.R., Jacobs-Lorena, M., 1994. A Drosophila third chromosome Minute locus encodes a ribosomal protein. Genetics 137, 513-520.

Andres, A.J., Thummel, C.S., 1994. Methods for quantitative analysis of transcription in larvae and prepupae. In: Goldstein, L.S.B., Fyrberg, E.A. (Eds.), Drosophila melanogaster: Practical Uses in Cell and Molecular Biology. Academic Press, London, pp. 565-573.

Ashburner, M., 1989. Drosophila: A Laboratory Manual. Cold Spring Harbor Laboratory Press, Cold Spring Harbor, NY.

Bairoch, A., 1993. The PROSITE dictionary of sites and patterns in proteins, its current status. Nucleic Acids Res. 21, 3097-3103.

Baumgartner, S., Martin, D., Chiquet-Ehrismann, R., 1993. Drosophila ribosomal protein S19 cDNA sequence. Nucleic Acids Res. 21, 3897

Birnstiel, M.L., Busslinger, M., Strub, K., 1985. Transcription termination and $3^{\prime}$ processing: the end is in site! Cell 41, 349-359.

Brown, N.H., Kafatos, F.C., 1988. Functional cDNA libraries from Drosophila embryos. J. Mol. Biol. 203, 425-437.

Cavener, D.R., 1987. Comparison of the consensus sequence flanking translational start sites in Drosophila and vertebrates. Nucleic Acids Res. 15, 1353-1361.

Chan, H.Y.E., Zhang, Y., O'Kane, C.J., 1997. Identification and characterization of the gene for Drosophila S20 ribosomal protein. Gene 200, 85-89.

Dorer, D.R., Anane-Firempong, A., Christensen, A.C., 1991. Ribosomal protein S14 is not responsible for the Minute phenotype associated with the $M(1) 7 C$ locus in Drosophila melanogaster. Mol. Gen. Genet. 230, 8-11.

Encyclopaedia of Drosophila Release 3.1, 1996. Berkeley Drosophila Genome Project.

Engels, W.R., Preston, C.R., Thompson, P., Eggleston, W.B., 1986. In situ hybridization of Drosophila salivary chromosomes with biotinylated DNA probes and alkaline phosphatase. Focus 8, 6-8.

Fried, H.M., Warner, J.R., 1981. Cloning of yeast gene for trichodermin resistance and ribosomal protein L3. Proc. Natl. Acad. Sci. USA $78,238-242$. 
Gloor, G.B., Preston, C.R., Johnson-Schlitz, D.M., Nassif, N.A., Phillis, R.W., Benz, W.K., Robertson, H.M., Engels, W.R., 1993. Type I repressors of $P$ element mobility. Genetics 135, 81-95.

Hoheisel, J.D., Lennon, G.G., Zehetner, G., Lehrach, H., 1991. Use of high coverage reference libraries of Drosophila melanogaster for relational data analysis; a step forwards mapping and sequencing of the genome. J. Mol. Biol. 220, 903-914.

Kay, M.A., Jacobs-Lorena, M., 1987. Developmental genetics of ribosome synthesis in Drosophila. Trends Genet. 3, 347-351.

Koettnitz, K., Kappel, B., Baumruker, T., Hauber, J., Bevec, D., 1994. The genomic structure encoding human initiation factor eIF5A. Gene 144, 249-252.

Kongsuwan, K., Quiang, Y., Vincent, A., Frisardi, M.C., Rosbash, M., Lengyel, J.A., Merriam, J., 1985. A Drosophila Minute gene encodes a ribosomal protein. Nature 317, 555-558.

Kuwano, Y., Wool, I.G., 1992. The primary structure of rat ribosomal protein L3. Biochem. Biophys. Res. Commun. 187, 58-64.

Liebich, I., Köhler, G., Witt, I., Gross, T., Käufer, N.F., 1994. Two genes encoding ribosomal protein L3 of Schizosaccharomyces pombe and their proximal promoter regions. Gene 142, 119-122.

Lindsley, D.L., Zimm, G.G., 1992. The Genome of Drosophila melanogaster. Academic Press, London.

McNabb, S.L., Ashburner, M., 1993. Identification of a Drosophila protein similar to rat S13 and archaebacterial S11 ribosomal proteins. Nucleic Acids Res. 21, 2523
Sambrook, J., Maniatis, T., Fritsch, E.F., 1989. Molecular Cloning: A Laboratory Manual, 2nd ed. Cold Spring Harbor Laboratory, Cold Spring Harbor, NY.

Schmidt, A., Hollmann, M., Schafer, U., 1996. A newly identified Minute locus, $M(2) 32 D$, encodes the ribosomal protein L9 in Drosophila melanogaster. Mol. Gen. Genet. 251, 381-387.

Schultz, L.D., Friesen, J.D., 1983. Nucleotide sequence of the $\mathrm{tcm} 1$ gene (ribosomal protein L3) of Saccharomyces cerevisiae. J. Bacteriol. $155,8-14$.

Tautz, D., Pfeifle, C., 1989. A non-radioactive in situ hybridization method for the localization of specific RNAs in Drosophila embryos reveals translational control of the segmentation gene hunchback. Chromosoma 98, 81-85.

Tautz, D., Hülskamp, M., Sommer, R.J., 1992. Whole mount in situ hybridization in Drosophila. In: Wilkinson, D.G. (Ed.), In Situ Hybridization: A Practical Approach. IRL Press, Oxford, pp. 61-73.

The FlyBase Consortium, 1997. FlyBase-a Drosophila database. Nucleic Acids Res. 25, 63-66.

Wool, I.G., Chan, Y.L., Gluck, A., 1996. Mammalian ribosomes: The structure and the evolution of the proteins. In: Hershey, J.W.B., Mathews, M.F., Sonenberg, N. (Eds.), Translational Control. Cold Spring Harbor Laboratory Press, Cold Spring Harbor, NY, pp. 685-732.

Zhu, X., Joh, K., Hori, K., 1996. Nucleotide sequence of ribosomal protein L3 cDNA and the exon-intron structure of $\mathrm{L} 3$ gene in the nematode, Caenorhabditis elegans. DNA Seq. 6, 299-302. 